\title{
Sustainable Education for the Twenty-First Century: Implementing Mandatory Experiential Learning into Ontario Public High Schools
}

\author{
Celeste Castelino \\ Pickering College, Canada
}

\begin{abstract}
The twenty-first century is at the forefront of a new digital age, encompassing the need for new skills and pedagogy. The current education curriculum upheld by the Ontario government, emphasizes important learning skills within a theoretical framework rather than an experiential one. Learning focused on memorization and obtaining above average grades is not sufficient preparation for students who will compete with ever-advancing automation in the workplace. It is skills that are acquired through their individual experiences and interactions in society that will distinguish them from their robotic counterparts. Currently, public secondary institutions in Ontario offer Cooperative Education opportunities although, it is not mandatory. An obligatory experiential learning program that encompasses a student's high school career will introduce both valued workplace skills and instill a sense of self-motivation, thus establishing them as instrumental contributors to the global economy.
\end{abstract}

\section{Introduction}

Every day, an average of 350,000 children are born into the world [11]. Today, 1.8 billion are able to attend school [7], and many will go on to higher education with opportunities to secure stable job positions after obtaining a degree. As of 2017, 67.8 per cent of the world's adult population is currently employed [15]. Historically, economic, social and religious factors have affected this number. However, today's workforce faces a unique challenge due to technological advances. Robotic processes have proved to be fundamental resources in the global work sphere, therefore establishing competition for applicants looking for work. These economic changes have shifted the harmony in prominent industries, resulting in changes to the status quo. Hence, educators, governments, foundations and education ministries must re-examine current curriculums and teaching methods to ensure relevance. It is essential that students are supported in the acquisition of critical thinking, communication, creative and problem-solving skills. Attributes such as these are imperative to humanity's separation from machines; they are the defining traits that make humans unique. Society is again on the brink of a new era, and relevant foundations must be established by our world's education providers to ensure that all current students will thrive in a civilization that co-exists with robotics.

\section{Changing Trends in Education and the Ontario Public System}

Today, new technologies are proving to be more efficient than humans, thus influencing employers to rethink their source of employment. Consequently, over 7.5 million retail jobs are at risk of automation, along with numerous other professions that only require a high school degree. Small changes are already visible in workplaces, whether it be the increased number of kiosks in fast-food restaurants, or store transactions made through smartphones [14]. Uncertain careers already encompass telemarketers, loan officers, cashiers, paralegal assistants, taxi drivers and fast-food cooks [13]. One of the leading intelligent systems predicted to be a valuable asset on factory floors is Baxter, a robot equipped with kitting, packaging, loading and material handling abilities [10]. Conversely, not all jobs are forecasted to be filled by humanity's technologically advanced counterparts. These include social workers, therapists, nutritionists, physicians and clergy [13]. Robots such as Baxter create competitive challenges for students entering the workplace, making it essential that education is relevant to the requirements of employers.

The notion of being able to adapt with the times and shifts in the economy is a dilemma that has challenged society since the dawn of enlightened civilizations. The first Industrial Revolution during the $1800 \mathrm{~s}$ is viewed as one of the most influential pinnacles of both economic and social reforms influencing contemporary ideals. Prior to the notion of education for all children, young people were primarily accustomed to acquiring domestic 
knowledge from their families and as apprentices of masters of guilds [6]. With the rise of capitalism dominating the economy, employable civilians - who were generally uneducated - sourced work in factories and as labourers working under hazardous conditions. In terms of education, schools were primarily controlled by the church with a curriculum based on religion and students instructed in secular teachings. By the mid-nineteenth century, it became apparent that education was necessary to prepare people for an industrial society and that traditional teachings were severely lacking [5]. Advocating for change commenced with concerned civilians, as enlightened individuals held lectures comparing America's system with other parts of the world. The Prussian system of the time, developed by J.H. Pestalozzi, stressed that education should encompass "hands-on" learning rather than memorization. American educator and educational reformer, Horace Mann, is credited for his successful campaigns in gaining political reform for education. He primarily triumphed in establishing the first school for teacher training, supporting access to free libraries in all districts and initializing awareness for much needed financial support for schools. Mann ensured education for every child and eventually compulsory attendance in schools [6]. The first industrial revolution was that of steel, factories and mechanization, but the principle ideologies and values of the time have trickled down through history to the fourth industrial revolution.

Once again society is faced with the challenge of embracing the technology associated with the time and the necessity to innovate [3]. In 1877, J.R. Buchanan, an American physician, expressed that "Education should be a preparation for life and should be like the life to which it prepares". At one point in time, evidence of a good student could be attributed to one's ability to memorize facts and ideas but with increased access to advancing technologies, employers are concerned with aspects that make humans unique and evolutionary - skills like critical thinking and problem solving are in high demand amongst job applicants and should be introduced to students before post-secondary education or employment. If employers' needs are changing, then it is imperative that the education system should adapt to suit the demand.

Today's education providers are once again struggling with a financial divide. Numerous forprofit education providers recognize the need for lifelong learning thus implementing partnerships with numerous companies such as General Electric and IBM. These connections offer students bachelorcompletion programs, educational badges and ensure that knowledge gaps are filled according to employers' needs. 'It means going to where the learners are, providing them with an educational roadmap customized for every walk of life" [1].
Independent schools such as Pickering College enrich their students' learning (while still adhering to the Ontario curriculum), with their Global Leadership Program. It challenges students to develop creative and critical thinking skills across their elementary and high school years through action-oriented projects which mirror the workplace [17]. By comparison, public schools immerse students into a more theoretical program rather than experiential learning (the process of learning through experience). As a result, the province is witnessing an increase of students who are receiving their Ontario High School diplomas lacking the ability to think critically, process thoughts properly, communicate effectively in social or public situations or convey thinking through writing. From the perspective of undergraduate university programs there are large first year dropout rates due to the lack of necessary skills that students need in order to be successful after their four years of high school [12]. Student resiliency - the notion that students are able to independently manage all aspects involved with being a student - is another area of the public education system that should be taken under scrutiny. According to the Conference Board of Canada, the province ranks a " $\mathrm{C}$ " in this categorycompared to the country only ranking a "B" [4]. Both for-profit and non-profit educational providers must be on the same level and provide access to the same opportunities, as 85 per cent of all learners are enrolled in the public system and lack access to schools with large research and development budgets [1].

In order for secondary students to be prepared for a competitive future, the current curriculum and pedagogy must adapt to provide relevant experiential learning and content that is crucial for universities and the workplace. Acquisition of important creative and problem-solving skills can be obtained by implementing mandatory experiential learning for students in Ontario secondary schools. In Ontario, public high schools currently offer Cooperative Education opportunities for their students. This entails that students in grade eleven and twelve can earn high school credits by completing semester-long unpaid work placements. Although this is a proactive attempt at providing young people with relevant workplace skills, it is not a mandatory requirement [18]. Moreover, co-op is not a university level course and many students disregard it as an irrelevant initiative towards their postsecondary applications and acceptance. Reliance on standardized knowledge may have been efficient for aspiring factory workers in the past but no longer can education balance on the pillars of past ideologies. Companies and employers require relevant knowledge and skills that are taught through both application and experiential strategies. 


\section{Implementing Mandatory Experiential Learning}

In the twenty-first century, education reform is imperative to the continuous growth of the global economy. This implies that its relevance to the adapting society is crucial to an economic wealth and wellbeing of a country. In Ontario, the pedagogy and curriculum of today's classrooms is exceedingly outdated, creating a disconnection in the skills that are required of our future workforce. In part, this is due to the lack of government funding, limited communication between prominent stakeholders, enhanced and creative learning programs that create financial barriers for some families, the inability for smaller businesses to join the conversations with related parties, and scarcity to rectify these detrimental aspects to students' learning. Importantly, courses with the integration of experiential learning must become a necessity in today's education system. Universities require prepared students with the ability to apply the knowledge learned in secondary education, rather than students who have memorized the content taught. Any machine or robot has the capacity to memorize information input into its system but lacks the capability to innovate and invent new concepts and theories. Hence, in order for students to thrive in an economy co-existing with robots, the education curriculum must be reformed to incorporate experiential learning techniques so that students may gain the creative and problem-solving skills that are required in university.

By implementing a compulsory program that facilitates the application of both academic and twenty-first century skills, all students will have the necessary tools to be successful in the changing job market. This should be in the form of a crosscurricular project that extends over the four years of high school. The structure is similar to that of the Global Leadership Program of Pickering College, where each grade is assigned a mandatory project that will build on the skills acquired in the previous year. The principal foundations of each task are structured on exploration of a student's interest in a career or subject area and the application of experiential learning. The model is outlined in Figure 1.

In grade nine, students will be exposed to the idea of problem solving and how it relates to STEAM learning. Using their acquired knowledge, pupils will create a rudimentary prototype that has the capacity to combat a prevalent issue in the world. Grade ten will continue to build upon the skills that students were introduced to last year by once again challenging their understanding of problem solving. However, in this grade, students will now have to employ critical thinking and communication to convey a solution to an issue in their community in the form of a presentation. Eventually students will have to define themselves in their respective careers and it is important for them to be able to voice their opinions. Not only will the presentation challenge their ability to explain their ideas, but also reinforce their selfmotivation and leadership skills throughout the process. In grade eleven, students will have the chance to explore their personal interests that will provide an indication of their future prospects. This is a great way for students to gain a sense of what is required of them in grade twelve and what postsecondary options are available. Grade twelve continues students' investigation into their interests with a ten-hour mandatory co-op experience. Many students disregard the traditional community service hour requirements to graduate from high school, which takes away from the nature of its purpose. With ten of the forty required hours designated to actually learning in the field that students are interested in, all students will have equal access to the benefits of experiential learning and preparation for postsecondary institutions.

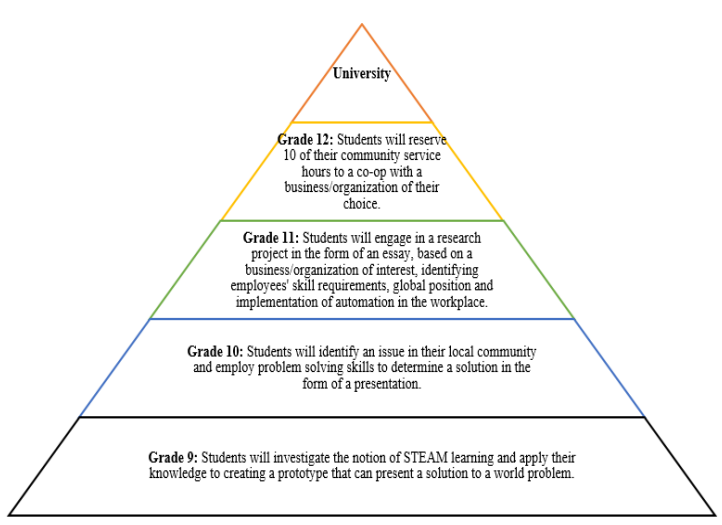

Figure 1. 'Mandatory Experiential Learning'

This mandatory model will be effective by introducing students to the notion of applying previous knowledge and establishing communication between companies and students - all while allowing them to explore their own interests. The implementation of an internship prior to postsecondary education will be instrumental in establishing interpersonal and business-related skills. These are imperative to future careers and gaining both academic (teachable abilities such as reading, math, digital literacy, etc.) and twenty-first century skills (communication, collaboration, innovation, creativity, critical thinking and problem solving) [9]. An implementation such as this is imperative to the future of student performance and will encourage students to assume independence in their community, thus introducing them to the need for self-awareness and self-motivation. Alignment between the secondary school system and post-secondary education is achievable through the implementation of the proposed obligatory measures and will promote 
action from interest groups who believe in the importance of an advanced pedagogy. This is the first step towards a stable and sustainable education system that will successfully shape the minds of our future leaders.

In the twenty-first century, education has become the determining factor for success of the future workforce. Skills that employers require in the workplace conflict with the present obsolete pedagogy and curriculum that do not consider our growing dependence on robotics. Students must be prepared for postsecondary education and future careers; school systems must adapt to the altering trends of society. The proposed model will ensure confidence in secondary schools across Ontario, as it enables students to gain academic and twenty-first century skills through an obligatory co-op opportunity in grade twelve. Students are introduced to problem solving, communication and experiential learning from grade nine to twelve, thus preparing them for similar demands in postsecondary education and the workplace.

People must determine what makes them unique and being exposed to this model of learning is imperative at early ages. The proposed solution will not only incorporate enrichment learning opportunities but will also allow students to pursue their own interests and be prepared to enter a diverse economy. This mandatory experiential learning program will ensure that students have the necessary resources to prepare themselves for a society where robots will one day live among humans.

\section{References}

[1] Aoun, Joseph E. How College Students Should Prepare for Our Automated Future. 26 September 2017. 15 March 2018.

[2] Brown-Martin, Graham. "Education and the Fourth Industrial Revolution.” (2017): 7-8.

[3] Chao Jr, Roger. "Educating for the fourth industrial revolution." The Chronicle of Education (2017).

[4] The Conference Board of Canada. "Education and Skills.” 2014.

[5] History.com Editors. Child labour. 27 October 2009. 15 March 2018.

[6] Galvin, Patrick. "The Industrial Revolution and its Educational Impacts”. (2003).

[7] Gapminder, The World has Reached Peak Number of Children! 4 May 2011. 8 March 2018

[8] Government of Ontario. "Education Funding in Ontario.” Ed, Education Equality Task Force, 2002. 11-12.
[9] Government of Ontario. "Innovation Agent Project (SEED)." 2016.

[10] Johnson, B. How Baxter the Robot Works. 23 January 2013. 13 March 2019.

[11] Lancaster, Eeva. Be Fruitful and Multiply! 13 June 2014. 8 March 2018.

[12] Maclean's. Canadian Universities with the highest (and lowest) graduation rates. 8 January 2008. 18 March 2019.

[13] Mahdawi, Arwa. What jobs will still be around in 20 years? Read this to prepare your future. 26 June 2017. 24 March 2018.

[14] McFarland, Matt. Robots: Is Your Job at Risk? 15 September 2017. 24 March 2018.

[15] OECD. OECD Employment Outlook. 13 June 2017. 8 March 2018.

[16] Ontario School Trustees. Module 10: Advocacy: Engaging the Public. 2018. 22 March 2018.

[17] Pickering College. Global Leadership Program. n.d. 15 March 2018.

[18] Settlement.org. What is Cooperative Education for High School Students? 27 July 2017. 2019 January 19

\section{Acknowledgements}

I would like to extend my most sincere thanks to all the staff and teachers at Pickering College who helped make this paper possible and my attendance to the Canadian International Conference on Education in Mississauga. An extra special thanks to Ms. Julia Hunt. 